\title{
Thrombocytosis Portends Adverse Prognosis in Colorectal Cancer: A Meta-Analysis of 5,619 Patients in 16 Individual Studies
}

\author{
DONGMIN GU ${ }^{1}$ and ARPAD SZALLASI ${ }^{2}$ \\ ${ }^{1}$ Department of Pathology, Saint Barnabas Medical Center, Livingston, NJ, U.S.A.; \\ ${ }^{2}$ Department of Pathology, Baptist Medical Center and Baptist - MD Anderson Cancer Center, Jacksonville, FL, U.S.A.
}

\begin{abstract}
Aim: The current study aimed to determine the prognostic significance of thrombocytosis in patients with colorectal cancer (CRC) by a meta-analysis of the literature. Patients and Methods: The meta-analysis followed the 2009 guidelines of Preferred Reporting Items for Systematic Reviews and Meta-Analyses. A systematic literature review was conducted from PubMed and Web of Science for articles published up to May 15, 2015. Sixteen studies with a total of 5,619 patients met the inclusion criteria. Hazard ratios and 95\% confidence intervals were retrieved from the original articles, calculated from the published Kaplan-Meier survival curves, or the corresponding authors were contacted for additional information. Heterogeneity was assessed using the $I^{2}$ statistic and Chi-square tests. Publication bias was assessed by Begg's funnel plot, Egger's linear regression test and trim-and-fill method. Sensitivity analysis was performed to validate the reliability. Results: Thrombocytosis is associated with shorter overall, disease-free and cancerspecific survival. Overall survival is reduced in patients with thrombocytosis regardless of their clinical tumor stage, and ethnicity. Shortened disease-free survival is associated with elevated platelet count in the non-specific stage (I-IV), localized tumor (stage I-III), and in the Asian patient population. Thrombocytosis is further associated with reduced cancer-specific survival in the non-specific stage and in Asian patients. Finally, thrombocytosis is significantly
\end{abstract}

This article is freely accessible online.

Correspondence to: Arpad Szallasi, Dept. Pathology, Baptist Medical Center, 800 Prudential Drive, Jacksonville, FL 32207, U.S.A. E-mail: Arpad.Szallasi@bmcjax.com

Key Words: Prognostic value, thrombocythemia, elevated platelet count, carcinoma, review. related to female patients, colon tumor location, T3-4 stage, lymph node positivity, metastasis, undifferentiated histology and lymphatic involvement. Conclusion: Thrombocytosis portends adverse prognosis in CRC, and may serve as a clinically useful marker to facilitate risk stratification and guide postoperative management.

Colorectal cancer (CRC) is one of the most common malignancies worldwide. In the United States, CRC is the third most commonly diagnosed cancer and the third leading cause of cancer-related death, accounting for approximately 140,000 new cases and 50,000 deaths in 2014 (1). In recent years, CRC has also become the third most common malignancy in China, with steadily increasing prevalence partially owing to the lack of public awareness and health authority support for early screening (2). In the past decade, there has been continued progress in the early detection and surgical management of CRC, resulting in a gradual decline in cancer mortality. However, the 5-year recurrence of CRC is persistently high, ranging between $10-40 \%$ (1). Patients with relapse have dismal outcomes despite chemoradiotherapy. Therefore, some experts advocate neoadjuvant chemotherapy or immediate postoperative chemotherapy for early-stage disease (stage I and II) (3). This may in theory reduce recurrence; however, it is associated with significant systemic toxicity. It is, thus, critical to establish reliable prognostic factors for risk stratifying the patients where the benefits of chemotherapy outweigh the possible risks.

Paraneoplastic thrombocytosis is defined as an abnormally elevated platelet count (usually $>400 \times 10^{3} / \mu \mathrm{l}$ ) in the blood circulation of patients with cancer (4). This phenomenon has been known for over 100 years. In fact, according to an early study, approximately one-third of patients with cancer may have thrombocytosis at the time of diagnosis, and $40 \%$ of patients with an elevated platelet count may also have cancer (5). Thrombocytosis has been studied in a variety of solid 
tumor types, including gynecological, lung, renal, gastric and breast carcinomas (6-11). Most studies in solid tumors have suggested that thrombocytosis is associated with reduced patient survival. Given that platelet measurement is standardized and readily available in every clinical laboratory, it is an attractive and practical surrogate marker for predicting disease course and for guiding clinical therapy.

Thrombocytosis in gastrointestinal cancer, including CRC, has also been widely reported $(9,12-14)$. Epidemiological studies investigating the association between thrombocytosis and CRC, however, failed to reach a consensus. For example, a Hungarian study concluded that patients with CRC with thrombocytosis and hepatic metastatic disease had worse overall (OS) and disease-free (DFS) survival (15). By contrast, a British study did not find any correlation between thrombocytosis and survival in a cohort of 630 patients (16).

Against this background, we performed a meta-analysis of all relevant published studies on this subject. Meta-analysis is a statistical approach of combining results from different studies into a common metric, and exploring the connection between study characteristics and findings. With this systematic approach, we wanted to better define the prognostic significance of thrombocytosis in the survival of patients with CRC.

\section{Patients and Methods}

Search strategy. A systematic literature review was conducted to assess the relationship of thrombocytosis and CRC. The search was performed in the PubMed (National Institutes of Health) and Web of Science (Thomson Reuters) databases for articles published up to May 15, 2015. The search terms included the following: "colon" or "colonic" or "rectum" or "rectal" or "colorectum" or "colorectal" or "cecum" or "cecal" or "appendix" or "appendiceal", and "thrombocytosis" or "thrombocythemia" or "platelet" or "thrombocyte", and "cancer" or "carcinoma". The search was conducted in free text in PubMed and in "title" and "topic" in the Web of Science. Furthermore, our search was broadened by the manual screening of the references of the identified publications. All scientific articles were independently reviewed by the Authors via the titles and abstracts. For articles for which inclusion or exclusion could not be determined based on the titles and abstracts, the full-text files were retrieved and analyzed. The disagreements were resolved through discussion. The meta-analysis followed the 2009 guidelines of Preferred Reporting Items for Systematic Reviews and Meta-Analyses (PRISMA) (17).

Study selection. Studies were considered eligible when meeting the following criteria: (i) prospective or retrospective epidemiological study design; (ii) examined the association of pre-treatment thrombocytosis with CRC. The exclusion criteria were as follows: (i) study population fewer than 50 patients; (ii) not published in English; (iii) letters, case reports, meeting abstracts, posters, editorial or review articles; (iv) median follow-up time less than 12 months; (v) cut-off value for defining thrombocytosis was vague; (vi) lack of data critical for evaluating the hazard ratio (HR) and its 95\% confidence interval (CI). For duplicated publications from the same research populations, the most comprehensive articles were included in our meta-analysis.

Data extraction. Data were independently extracted from candidate studies by the Authors. In particular, a pre-established form was used to standardize the information recorded, including the name of the first author, year of publication, geographic location, the size of the study population, clinical stage, follow-up period, cut-off value and statistical method of the survival analysis. HR of the survival analyses and $95 \%$ CI were retrieved from the original articles as the endpoints of the meta-analysis. For articles lacking HR or 95\% CI, the values were calculated using the Kaplan-Meier survival curves from the original articles, or the corresponding authors were contacted for additional information. For articles containing both univariate and multivariate analyses, the latter was chosen owing to combinatorial effects. Within the eligible studies, five articles investigated the relationship between thrombocytosis and pathological features of CRC (14, 18-21). The following features were analyzed by our study to determine their individual effect on survival: gender, tumor location, histology, TNM classification, lymphatic and venous involvement.

Statistical analysis. Heterogeneity of HR was assessed using the $\mathrm{I}^{2}$ statistic and Chi-square tests. When $\mathrm{I}^{2}$ was great than $50 \%$, heterogeneity was considered present and the random-effects model was used; otherwise the fixed-effects model was used. A pooled odds ratio (OR) greater than 1 indicated that a significant association existed between thrombocytosis and pathological characteristics of CRC. Publication bias was accessed by Begg's funnel plot, Egger's linear regression test and trim-and-fill method. Sensitivity analysis was performed to validate the reliability. Twosided $p$-values of less than 0.05 were considered statistically significant. In our study, heterogeneity analysis, publication bias, sensitivity analysis and pooled ORs were conducted or analyzed in STATA 12.0 software (StatCorp, College Station, TX, USA).

\section{Results}

Eligible studies. We searched the PubMed and Web of Science databases with the noted key words and identified 918 candidate articles. Of these, we excluded 149 duplicates, 13 case reports, 13 reviews, eight meeting abstracts, eight letters, one poster and one editorial opinion. We then screened the titles and abstracts of the remaining 725 articles. Based on the inclusion criteria as outlined in the Materials and Methods, we selected 35 publications to further determine their eligibility (13-16, 18-45). We included 30 studies for the meta-analysis given that they fulfilled the exclusion criteria: full-text article with a study population great than 50; explicit cut-off value for defining thrombocytosis; and more than 12 months follow-up (13-15, 18-22, 25-28, 30-35, 37-45). Of these 30 studies, however, we had to eliminate 14 due to their lack of survival analysis or because data were insufficient for calculating HRs. For example, we excluded the 2015 study of Jósa et al. (33) because we realized that Baranyai et al. (15) studied the same population and included the same results. We illustrate the search process in Figure 1. Finally, we chose 16 studies 


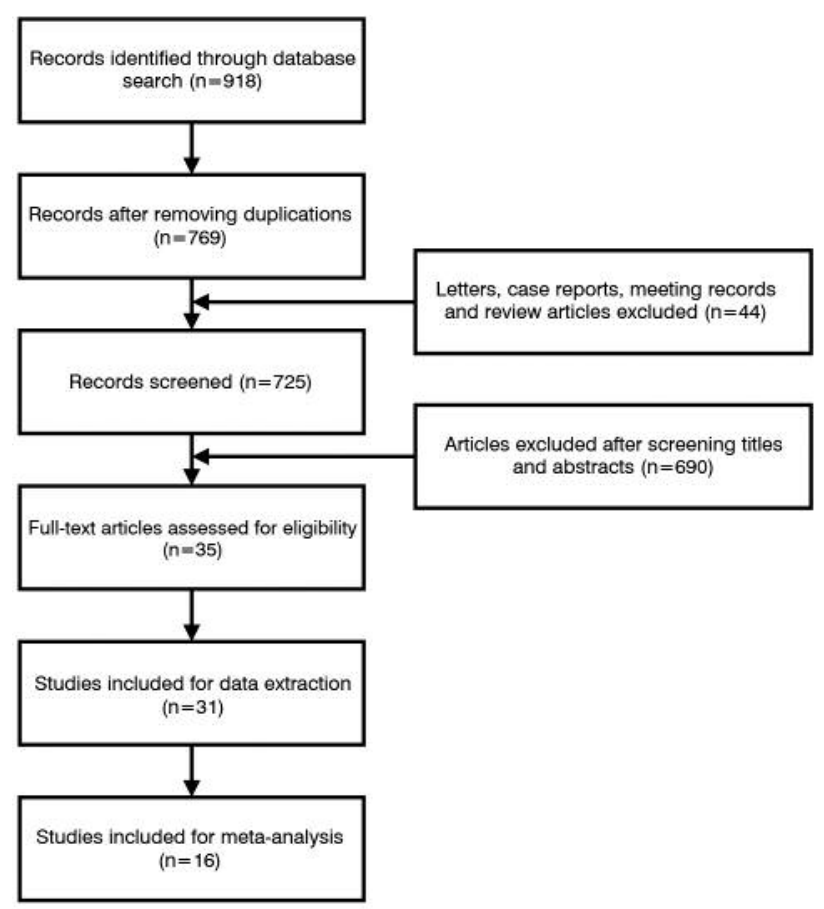

Figure 1. Flowchart of article selection.

with a total of 5,619 patients for our meta-analysis of thrombocytosis in patients with CRC $(14,15,18-21,37-45)$.

As shown in Table I, all studies were published within the past 5 years. The study cohort included one study each from China and Mexico, two studies each from Korea, Hungary, United Kingdom and the United States of America, five studies from Japan, and one joint study from Japan and Korea. The number of patients per study varied, with a median of 238 patients and range of 1,463 . It is noteworthy that the study by Wan et al. included 1,513 patients with a median follow-up of 46.7 months (40). The cut-off value for defining thrombocytosis also varied, with $60 \%$ of the studies (9/15) applying a value of $400 \times 10^{3} / \mu 1$.

\section{Meta-analysis}

Heterogeneity. We evaluated the prognostic significance of thrombocytosis by comparing the survival of patients with thrombocytosis to that of patients with a normal platelet count. Of the selected studies, 13 examined OS, eight examined DFS and four examined cancer-specific survival (CSS) (Figure 2). With regard to OS, defined as the period from cancer diagnosis or treatment to death, our results indicate that thrombocytosis is associated with shorter OS $(\mathrm{HR}=1.61,95 \% \mathrm{CI}=1.19-2.04)$. Of note, we used a randomeffects model in the presence of heterogeneity $\left(\mathrm{I}^{2}=66.5 \%\right.$, $p<0.001)$. The studies proposing a strong poor prognostic role of thrombocytosis in CRC included those of CraviotoVillanueva et al. (43), Kaneko et al. (20), Jósa et al. (45), and Toiyama et al. (21). For DFS, a greater HR was observed in our study cohort $(\mathrm{HR}=1.96,95 \% \mathrm{CI}=1.23-2.69)$ with a random-effects model $\left(\mathrm{I}^{2}=69.3 \%, p=0.002\right)$. For CSS, we applied a fixed-effects model in the absence of heterogeneity $\left(\mathrm{I}^{2}=20.0 \%, p=0.290\right)$, finding a HR of 1.82 and $95 \% \mathrm{CI}=1.04-2.59$.

Next, we stratified the analysis according to the clinical tumor stage: non-specified (all stages), localized tumor (stage I-III) and metastatic disease (stage IV) to identify the source of heterogeneity. For the non-specified stage (Figure $3 \mathrm{~A}$ ), seven articles studied OS, three studied DFS and three studied CSS, reporting poorer OS $(\mathrm{HR}=1.61,95 \% \mathrm{CI}=1.36$ 1.87), DFS $(\mathrm{HR}=2.33,95 \% \mathrm{CI}=1.65-3.00)$ and $\mathrm{CSS}$ $(\mathrm{HR}=1.69,95 \% \mathrm{CI}=1.04-2.34)$. We found no significant heterogeneity in the non-specified stage. For the localized tumor (stage I-III), three articles each reported OS and DFS. Elevated thrombocyte count was associated with shorter OS $(\mathrm{HR}=1.92,95 \% \mathrm{CI}=0.64-4.47)$ and DFS $(\mathrm{HR}=1.42,95 \%$ $\mathrm{CI}=0.61-2.24)$. We found no heterogeneity when analyzing the OS for patients with localized tumor $\left(\mathrm{I}^{2}=25.9 \%\right.$, $p=0.259)$. On the contrary, we identified heterogeneity in the DFS of those with localized tumor $\left(\mathrm{I}^{2}=56.4 \%, p=0.101\right.$; Figure 3B). Furthermore, with regard to the metastatic stage (stage IV), all three articles reported OS and showed an elevated platelet count portended worse OS (HR=3.60. 95\% $\mathrm{CI}=1.62-5.58)$ with no heterogeneity present $\left(\mathrm{I}^{2}=0.0 \%\right.$, $p=0.762$; Figure 3C).

Lastly, we investigated the impact of ethnicity on patient survival. We divided the study cohort into Asian, British and American, and other (Mexico and Hungary). In the Asian group, there were five OS, four DFS and three CSS studies, respectively. Meta-analysis of the Asian population showed that an elevated thrombocyte count was associated with poorer OS $(\mathrm{HR}=1.52,95 \% \mathrm{CI}=1.06-1.97)$, $\mathrm{DFS}(\mathrm{HR}=2.29$, 95\% $\mathrm{CI}=1.65-2.93)$ and $\mathrm{CSS}(\mathrm{HR}=2.22,95 \% \mathrm{CI}=1.19-3.25)$ with no significant heterogeneity revealed (Figure 4A). The British and American groups included four OS, two DFS and one CSS study, and only the OS was sufficient for analysis (Figure 4B). Here we observed worse OS (HR=1.42, 95\% $\left.\mathrm{CI}=0.87-1.97, \mathrm{I}^{2}=82.6 \%, p=0.001\right)$ with thrombocytosis. The last category contained four OS and two DFS (not analyzed due to data insufficiency) studies conducted in Mexico and Hungary. Our analysis showed an elevated platelet count was associated with poor $\mathrm{OS}(\mathrm{HR}=2.07,95 \% \mathrm{CI}=1.22-2.92$, $\mathrm{I}^{2}=2.7 \%, p=0.379$; Figure 4C).

Thrombocytosis and clinicopathological features of CRC. Among the included 16 studies, five investigated pathological features such as tumor location, histology, TNM classification, and lymphatic and venous involvement (4, 18-21). We performed a meta-analysis of these variables. As shown in 
Table I. Major characteristics of the eligible studies.

\begin{tabular}{|c|c|c|c|c|c|c|c|}
\hline Author (Ref) & Year & Country & $\begin{array}{l}\text { No. of } \\
\text { patients }\end{array}$ & $\begin{array}{c}\text { Clinical } \\
\text { stage }\end{array}$ & $\begin{array}{r}\text { Survival } \\
\text { analysis }\end{array}$ & $\begin{array}{l}\text { Median (range) } \\
\text { follow-up }\end{array}$ & $\begin{array}{l}\text { Cut-off value } \\
\left(\times 10^{3} / \mu \mathrm{l}\right)\end{array}$ \\
\hline Baranyai et al. (15) & 2014 & Hungary & 454 & I-IV & OS, DFS & 36.1 Months & 400 \\
\hline Kozak et al. (42) & 2015 & USA & 129 & I-III & DFS, OS & 24.7 (4.2-101.7) Months & 400 \\
\hline Cravioto-Villanueva et al. (43) & 2012 & Mexico & 163 & 0 -III & OS & 35.4 (2-216) Months & 350 \\
\hline Kim et al. (18) & 2014 & Japan, Korea & 314 & I-III & DFS, CSS & $36.0(2.0-78.0)$ Months & 370 \\
\hline Ishizuka et al. (14) & 2012 & Japan & 453 & I-IV & OS & 1,196.0 Days & 300 \\
\hline Sasaki et al. (12) & 2011 & Japan & 636 & I-IV & CSS, DFS & 49.1 Months & 370 \\
\hline Qiu et al. (19) & 2010 & China & 363 & I-IV & OS & $26.0(3.0-50.0)$ Months & 400 \\
\hline Wan et al. (40) & 2013 & USA & 1,513 & 0 -IV & OS & 46.7 (19.6-84.7) Months & 400 \\
\hline Kawai et al. (44) & 2012 & Japan & 108 & 0-IV & DFS & 22.5 Months & 365 \\
\hline Neal et al. (38) & 2009 & UK & 174 & IV & DFS, OS & 36 (6-69) Months & 400 \\
\hline Kaneko et al. (20) & 2012 & Japan & 50 & I-IV & OS & $17.0(0.77-61.6)$ Months & 400 \\
\hline Choi et al. (39) & 2014 & Korea & 105 & I-IV & CSS & 44 (2-81) Months & 400 \\
\hline Paik et al. (37) & 2014 & Korea & 600 & I-IV & OS, CFS & 27.4 \pm 18.2 Months* & 400 \\
\hline Jósa et al. (45) & 2015 & Hungary & 166 & IV & OS, DFS & 28 Months** & 380 \\
\hline Neal et al. (41) & 2015 & UK & 302 & I-IV & CSS, OS & 29.7 (4-96) Months & 400 \\
\hline Toiyama et al. (21) & 2015 & Japan & 89 & I-III & DFS, OS & 56 (2-147) Months & 300 \\
\hline
\end{tabular}

OS: Overall survival; DFS: disease-free survival; CSS: cancer-specific survival; CFS: cancer progression-free survival. *Mean \pm standard deviation; **mean.

Table II. Meta-analysis of the association between thrombocytosis and clinicopathological features of colorectal cancer.

\begin{tabular}{|c|c|c|c|c|c|c|}
\hline Variable & Comparison & Number of Studies & Pooled OR & $95 \% \mathrm{CI}$ & $\mathrm{I}^{2}(\%)$ & $p$-Value \\
\hline Gender & Female versus male & 5 & 1.37 & $1.06-1.78$ & 0.0 & 0.769 \\
\hline Histology & Undifferentiated versus differentiated & 4 & 1.58 & $0.94-2.67$ & 0.0 & 0.937 \\
\hline Location & Colon versus rectum & 3 & 1.65 & $1.06-2.55$ & 37.4 & 0.202 \\
\hline $\mathrm{T}$ & $\mathrm{T} 3-4$ versus $\mathrm{T} 1-2$ & 3 & 2.53 & $1.15-5.57$ & 33.9 & 0.220 \\
\hline $\mathrm{N}$ & Positive versus negative & 4 & 1.43 & $1.09-1.88$ & 0.0 & 0.997 \\
\hline M & Positive versus negative & 2 & 2.03 & $1.34-3.07$ & 0.0 & 0.764 \\
\hline Lymphatic involvement & Positive versus negative & 2 & 1.25 & $0.58-2.70$ & 74.6 & 0.047 \\
\hline Venous involvement & Positive versus negative & 2 & 1.01 & $0.36-2.86$ & 87.6 & 0.005 \\
\hline
\end{tabular}

T: Tumor of the TNM classification; N: lymph node of the TNM classification; M: metastasis of the TNM classification; OR: odds ratio; CI: confidence interval.

Table II, thrombocytosis had a significant association with female gender, tumor location in the colon, higher pathological T-stage, pathological positive N-stage, pathological positive $\mathrm{M}$ stage, undifferentiated histology, and lymphatic involvement. Meanwhile, we noted no heterogeneity except for lymphatic and venous involvement (Table II).

Publication bias and sensitivity analysis. Following the criteria by the Cochrane Handbook for Systematic Reviews of Interventions (46), we analyzed the publication bias in the OS group with more than 10 studies. Our Begg's test result revealed an asymmetric funnel plot. Egger's regression test showed that the bias coefficient was -0.005 (95\% CI $=-0.010$ to -0.001 , $\mathrm{t}$-value $=-2.63$ and $p=0.024)$. To this end, we performed a trim-and-fill analysis to further assess the publication bias. The test showed a symmetrical funnel plot: this implies a "well-behaved" data set in which publication bias is unlikely (Figure 5).

Lastly, we removed each study stepwise to perform the sensitivity analysis. Our results showed no significant change, indicating the reliability of our meta-analysis.

\section{Discussion}

Platelets play a crucial role in a variety of biological processes, ranging from hemostasis and vascular integrity through immunity to inflammation (47). An elevated platelet count, termed thrombocytosis, has been found in various pathological 


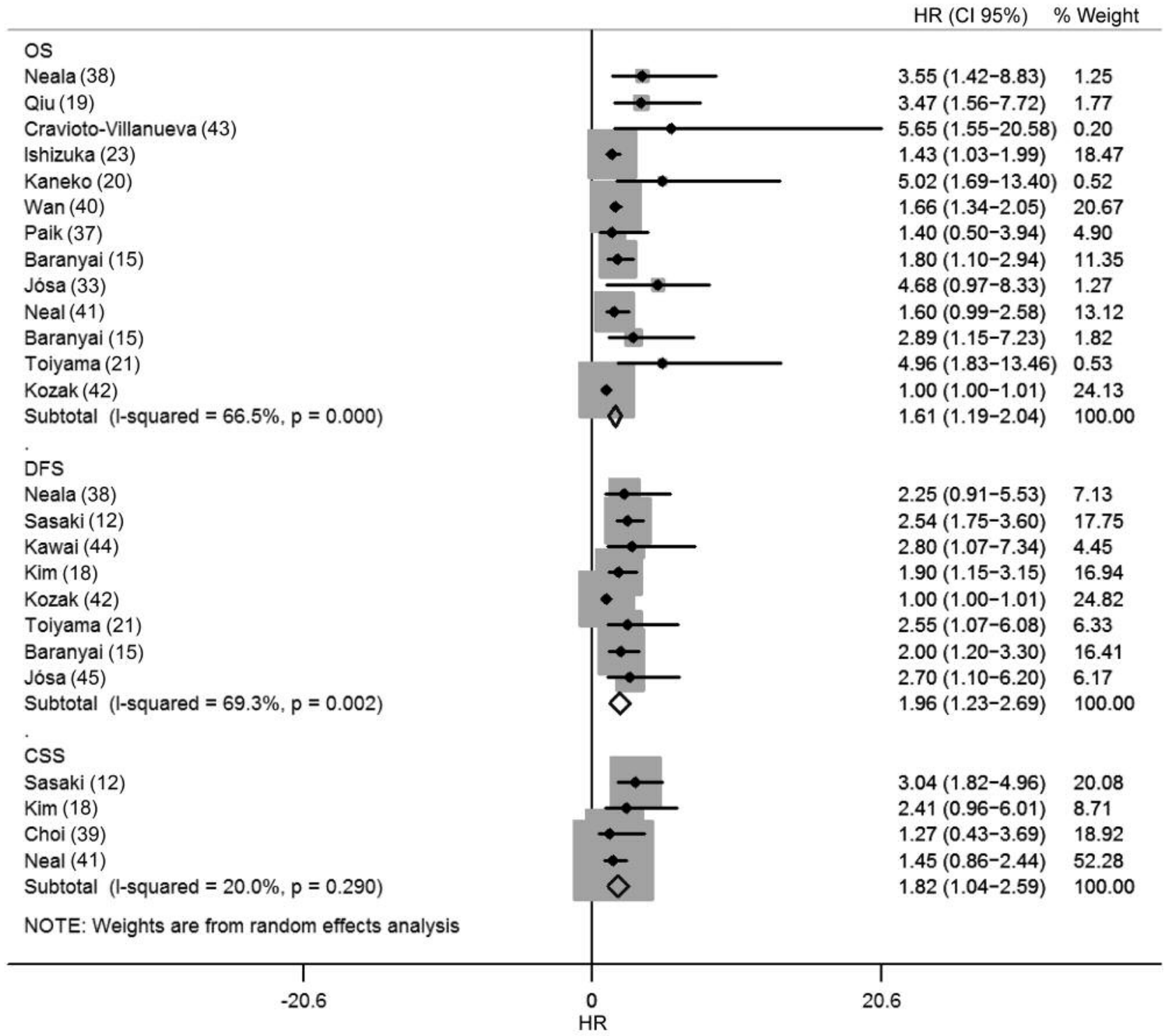

Figure 2. Forest plot of patient survival. Meta-analysis indicates thrombocytosis is associated with shorter overall (OS), disease-free (DFS) and cancer-specific (CSS) survival in patients with colorectal carcinoma. HR: Hazard ratio; CI: confidence interval.

conditions. Platelets may rise in myeloproliferative disorders (primary thrombocytosis), or become elevated secondary to events such as infection, inflammation, trauma, surgery, and iron deficiency (secondary thrombocytosis).

A special form of secondary thrombocytosis, termed paraneoplastic thrombocytosis, is associated with cancer. First reported in 1964 (5), paraneoplastic thrombocytosis phenomenon is now recognized as a poor prognostic indicator in many types of cancer including lung, gastric, breast, renal and gynecological cancer (6-11). It is only beginning to be understood how thrombocytosis is generated by cancer and how this may impair patient survival. Neoplasms are known to synthesize cytokines including interleukin (IL6). IL6 can enhance thrombopoietin production in the liver, which, in turn, may stimulate megakaryocytes in the marrow to produce platelets in excess (48). Circulating platelets may promote tumor growth via secretion of angiogenic or tumor growth factors, such as plateletderived epidermal growth factor, thrombospondin and vascular endothelial growth factor (48). In addition, platelets may protect circulating tumor cells from attacks by the host immune system, thereby facilitating cancer metastasis (49).

There is increasing evidence that patients with $\mathrm{CRC}$ with 
A

\begin{tabular}{|c|c|c|c|}
\hline & & $\mathrm{HR}(\mathrm{Cl} 95 \%) \%$ & $\%$ Weight \\
\hline \multicolumn{4}{|l|}{ os } \\
\hline Baranyai (15) & $\rightarrow$ & $1.80(1.10-2.94)$ & 7.62 \\
\hline Ishizuka (14) & 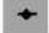 & $1.43(1.03-1.99)$ & 27.98 \\
\hline Qiu (19) & & $3.47(1.56-7.72)$ & 0.68 \\
\hline Wan $(40)$ & & $1.66(1.34-2.05)$ & 51.15 \\
\hline \multicolumn{4}{|c|}{$5.02(1.69-13.40) \quad 0.19$} \\
\hline Paik (37) & $\rightarrow$ & $1.40(0.50-3.94)$ & 2.18 \\
\hline Neal (41) & + & $1.60(0.99-2.58)$ & 10.21 \\
\hline Subtotal $(1-$ squared $=0.0 \%, p=0.737)$ & 0 & $1.61(1.36-1.87)$ & 100.00 \\
\hline \multicolumn{4}{|l|}{ DFS } \\
\hline Sasaki (12) & & $2.54(1.75-3.60)$ & 53.67 \\
\hline Kawai (44) & & $2.80(1.07-7.34)$ & 4.67 \\
\hline Baranyai (15) & & $2.00(1.20-3.30)$ & 41.65 \\
\hline Subtotal $(1-$ squared $=0.0 \%, p=0.718)$ & & $2.33(1.65-3.00)$ & 100.00 \\
\hline \multicolumn{4}{|l|}{ css } \\
\hline Sasaki (12) & & $3.04(1.82-4.96)$ & 16.91 \\
\hline Chol (39) & & $1.27(0.43-3.69)$ & 15.73 \\
\hline Neal (41) & $\rightarrow$ & $1.45(0.86-2.44)$ & 67.36 \\
\hline Subtotal $(1-$ squared $=42.1 \%, p=0.178)$ & & $1.69(1.04-2.34)$ & 100.00 \\
\hline 1 & \multicolumn{3}{|c|}{1} \\
\hline-13.4 & \multicolumn{3}{|c|}{13.4} \\
\hline
\end{tabular}

B

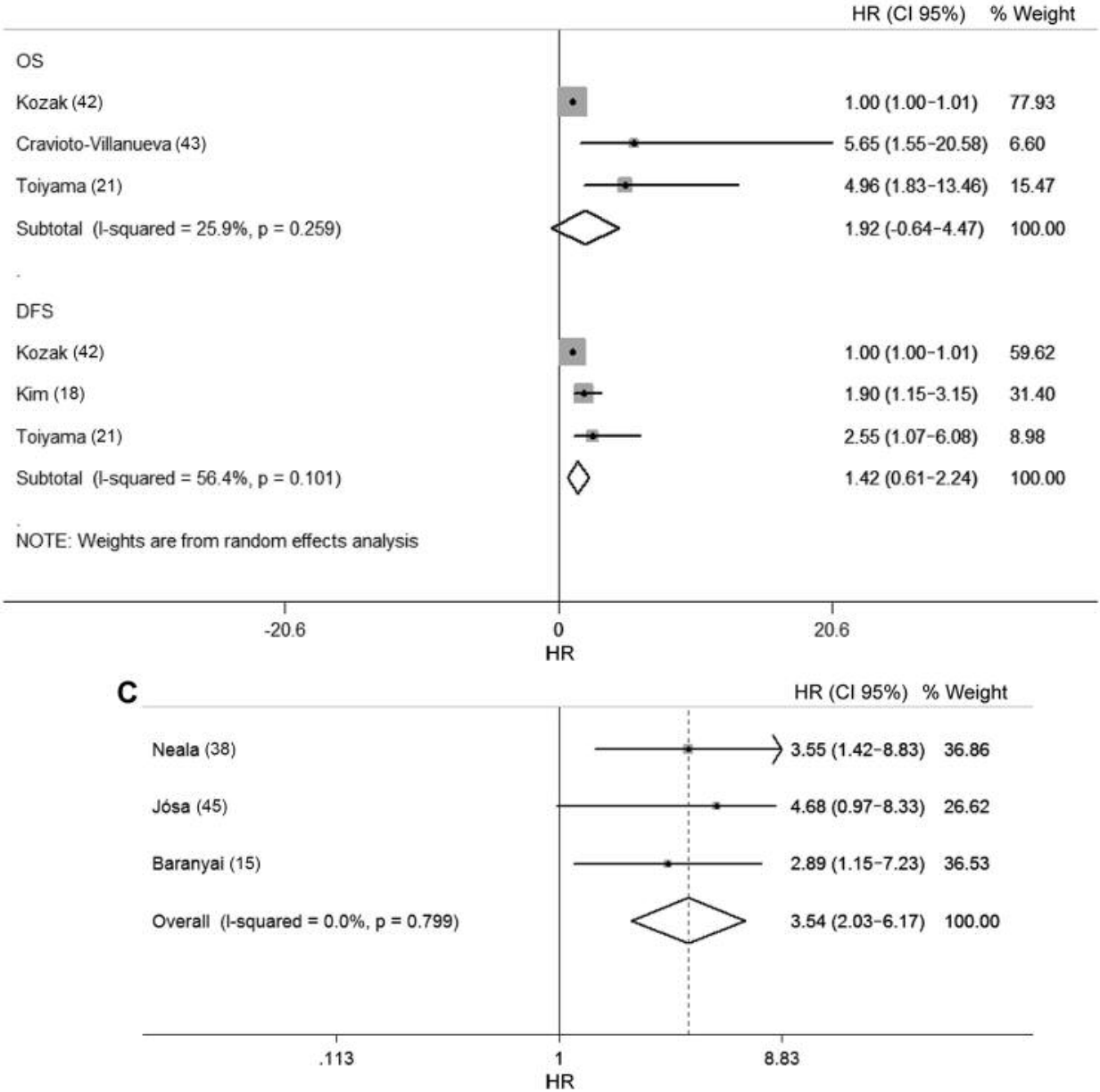

Figure 3. Forest plot analysis of patient survival according to clinical tumor stage of colorectal cancer. Thrombocytosis is associated with poorer overall (OS), disease-free (DFS) and cancer-specific (CSS) survival in patients with tumor of non-specified stage (all stages) (A), with shorter OS and DFS in patients with localized tumor (stage I-III) (B), and with worse OS in the metastatic group (stage IV). HR: Hazard ratio; CI: confidence interval. 
A

HR (Cl 95\%) \% Weight

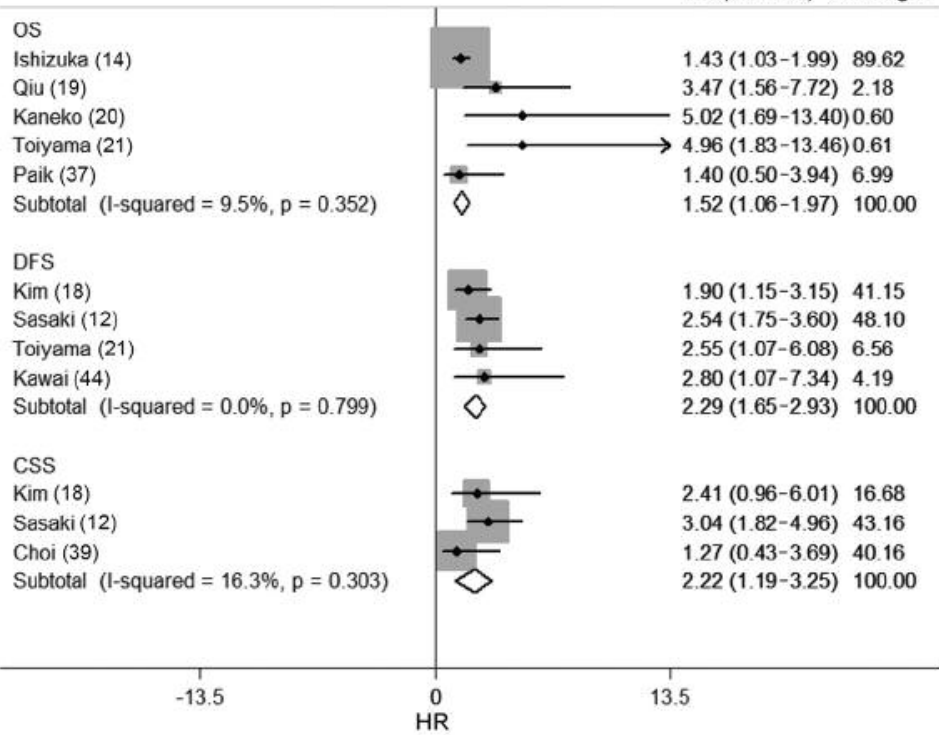

B

$\mathrm{HR}(\mathrm{Cl} 95 \%) \quad \%$ Weight

OS

Neala (38)

Neal (41)

Kozak (42)

Wan (40)

Subtotal (1-Squared $=82.6 \%, p=0.001)$

HR (CIO5\%)

NOTE: Weights are from random effects analysis



C

HR

$\begin{array}{ll}3.55(1.42-8.83) & 2.10 \\ 1.60(0.99-2.58) & 22.11 \\ 1.00(1.00-1.01) & 40.85 \\ 1.66(1.34-2.05) & 34.94 \\ 1.42(0.87-1.97) & 100.00\end{array}$

os

Cravioto-Villanueva (43)

Baranyai (15)

Baranyai (metastasis) (15)

Jósa (45)

Subtotal $(1-$ squared $=2.7 \%, p=0.379)$

\begin{tabular}{lll} 
& & \\
\hline-20.6 & 0 & 20.6 \\
HR
\end{tabular}

Figure 4. Forest plot analysis of patient survival according to ethnicity. Thrombocytosis is associated with shorter overall (OS), disease-free (DFS) and cancer-specific (CSS) survival in the Asian group (A), with worse OS in the British and American group (B), and poorer OS in the group of other ethnicity (Mexico and Hungary) (C). HR: Hazard ratio; CI: confidence interval. 


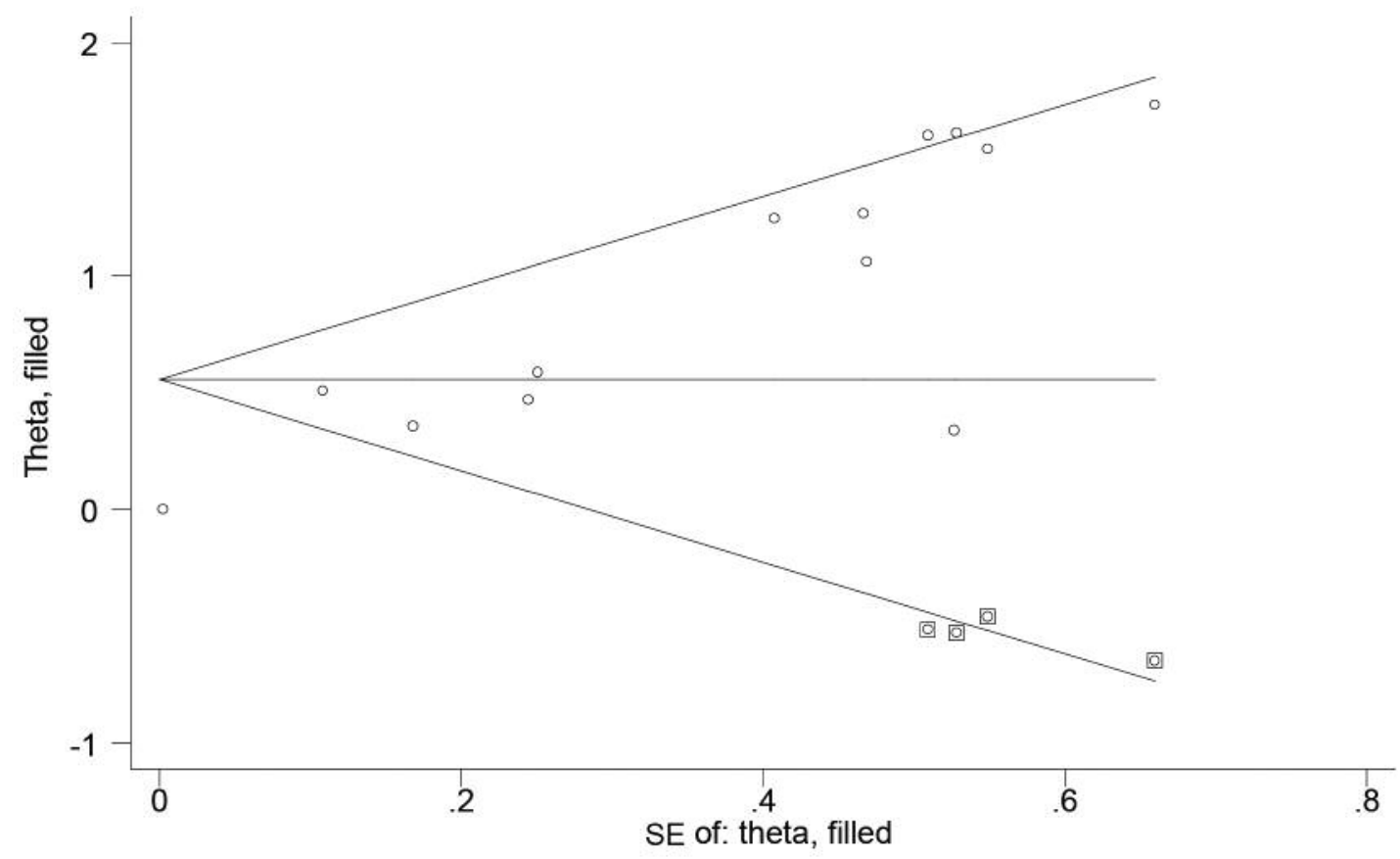

Figure 5. Hazard ratio funnel plots with pseudo 95\% confidence interval of studies investigating the association between thrombocytosis and overall survival. Thirteen datasets (circles) represent the studies included in this analysis. Four datasets (circles with outer squares) represent the virtual studies with which the analysis shows a symmetrical funnel plot.

thrombocytosis have worse OS due to a combination of higher recurrence and metastatic disease. In node-positive disease, the importance of thrombocytosis was reported to be equivalent to lymph node positivity (26). In node-negative patients, thrombocytosis was independently associated with DFS and OS in multivariate analysis, together with tumor depth, grade and lymphatic invasion (13). Patients with CRC with preoperative thrombocytosis prior to chemoradiotherapy had lower rates of radiographic and pathological response (44).

Although most studies implicated thrombocytosis as a negative prognostic factor in CRC, other studies were unable to replicate this observation. For example, Nyasavajjala et al. analyzed 630 consecutive patients with CRC from 2004 to 2007 and concluded that preoperative thrombocytosis was not a prognostic indicator of survival in patients with CRC regardless of pathological stage (16). This inconsistency in the literature prompted us to conduct this meta-analysis. Metaanalysis with systematic review of the literature allows the conclusive synthesis of existing scientific evidence. To many, it represents the top of the hierarchy of research methods.

Our meta-analysis of 16 independent studies with 5,619 patients unequivocally supports an adverse prognostic significance for thrombocytosis. The included studies contained multiple pathological and demographic features that allowed us to analyze the impact of thrombocytosis on different subgroups. Our study suggests that thrombocytosis is reliable predictor of unfavorable prognosis (OS and DFS) regardless of tumor clinical stage and ethnicity. The five studies in Table II allowed us to further individually analyze the clinicopathological features of CRC. We found CRC with thrombocytosis was remarkably associated with pathological T3, T4, N and M stages, undifferentiated histology, lymphatic involvement, colon tumor location (versus rectum) and the female population. Venous involvement, on the contrary, was not associated with paraneoplastic thrombocytosis.

Clearly, meta-analysis has its own limitations (50). For instance, publication bias could compromise the quality of the meta-analysis. We detected publication bias in our study when investigating the association of thrombocytosis and OS. For example, the important negative study by Nyasavajjala et al. was excluded from our analysis due to the lack of a survival curve and HRs (16). Publication bias can also be introduced by excluding studies with smaller study populations, or articles published in languages other than English. Studies with negative results may never have been published. The limited number of studies precluded us from conducting an adequate assessment of publication bias and sensitivity analysis.

Heterogeneity is another common concern in metaanalysis (51). After detecting heterogeneity in the analysis, we conducted subgroup studies to validate the results and hoped to pinpoint the source of heterogeneity. The subgroup 
analysis revealed that DFS for patients with localized disease, and OS and DFS in the British and American populations could be a source of heterogeneity. In addition, American (and British) patient populations can be racially mixed. We also speculated two other potential factors that might have contributed to the heterogeneity. Firstly, there was great difference in the follow-up time, ranging from 17 to 65 months. Secondly, there was no agreed definition of thrombocytosis. The cut-off values for defining thrombocytosis were likely determined by the hospital committees and local populations. This appears to the same issue that has been faced by the meta-analyses of thrombocytosis in other cancer types (52). Lastly, our metaanalysis is an observational study of retrospective studies. It is more likely to be affected by inherent recall and selection biases than prospective randomized controlled studies.

In summary, our meta-analysis suggests that thrombocytosis heralds a worse prognosis in patients with CRC. Thus, thrombocytosis may serve as a clinically useful marker for facilitating risk stratification and guiding postoperative management. To our knowledge, the present study represents the first systematic review and metaanalysis of thrombocytosis in CRC.

\section{Conflicts of Interest}

None.

\section{Funding}

The Authors received no funding for this work.

\section{References}

1 Siegel R, Desantis C and Jemal A: Colorectal cancer statistics, 2014. CA Cancer J Clin 64: 104-117, 2014

2 Liu S, Zheng R, Zhang M, Zhang S, Sun X and Chen W: Incidence and mortality of colorectal cancer in China, 2011. Chin J Cancer Res 27: 22-28, 2015.

3 Hong TS and Ryan DP: Adjuvant chemotherapy for locally advanced rectal cancer: Is it a given? J Clin Oncol 33: 1878$1880,2015$.

4 Lin RJ, Afshar-Kharghan V and Schafer AI: Paraneoplastic thrombocytosis: the secrets of tumor self-promotion. Blood 124 : 184-187, 2014.

5 Levin J and Conley CL: Thrombocytosis associated with malignant disease. Arch Intern Med 114: 497-500, 1964.

6 Stone RL, Nick AM, McNeish IA, Balkwill F, Han HD, Bottsford-Miller J, Rupairmoole R, Armaiz-Pena GN, Pecot CV, Coward J, Deavers MT, Vasquez HG, Urbauer D, Landen CN, $\mathrm{Hu}$ W, Gershenson H, Matsuo K, Shahzad MM, King ER, Tekedereli I, Ozpolat B, Ahn EH, Bond VK, Wang R, Drew AF, Gushiken F, Lamkin D, Collins K, DeGeest K, Lutgendorf SK, Chiu W, Lopez-Berestein G, Afshar-Kharghan V and Sood AK: Paraneoplastic thrombocytosis in ovarian cancer. N Engl J Med 366: 610-618, 2012.

7 Pedersen LM and Milman N: Prognostic significance of thrombocytosis in patients with primary lung cancer. Eur Respir J 9: 1826-1830, 1996

8 Hernandez E, Lavine M, Dunton CJ, Gracely E and Parker J: Poor prognosis associated with thrombocytosis in patients with cervical cancer. Cancer 69: 2975-2977, 1992.

9 Ikeda M, Furukawa H, Imamura H, Shimizu J, Ishida H, Masutani S, Tatsuta M and Satomi T: Poor prognosis associated with thrombocytosis in patients with gastric cancer. Ann Surg Oncol 9: 287-291, 2002.

10 Bensalah K, Leray E, Fergelot P, Rioux-Leclercq N, Tostain J, Guille F and Patard JJ: Prognostic value of thrombocytosis in renal cell carcinoma. J Urol 175: 859-863, 2006.

11 Taucher S, Salat A, Gnant M, Kwasny W, Mlineritsch B, Menzel RC, Schmid M, Smola MG, Stierer M, Tausch C, Galid A, Steger G, Jakesz R, Austrian B and Colorectal Cancer Study G: Impact of pretreatment thrombocytosis on survival in primary breast cancer. Thromb Haemost 89: 1098-1106, 2003.

12 Sasaki K, Kawai K, Tsuno NH, Sunami E and Kitayama J: Impact of preoperative thrombocytosis on the survival of patients with primary colorectal cancer. World J Surg 36: 192-200, 2012.

13 Kandemir EG, Mayadagli A, Karagoz B, Bilgi O, Turken O and Yaylaci M: Prognostic significance of thrombocytosis in nodenegative colon cancer. J Int Med Res 33: 228-235, 2005.

14 Ishizuka M, Nagata H, Takagi K, Iwasaki Y and Kubota K: Preoperative thrombocytosis is associated with survival after surgery for colorectal cancer. J Surg Oncol 106: 887-891, 2012.

15 Baranyai Z, Krzystanek M, Josa V, Dede K, Agoston E, Szasz AM, Sinko D, Szarvas V, Salamon F, Eklund AC, Szallasi Z and Jakab F: The comparison of thrombocytosis and plateletlymphocyte ratio as potential prognostic markers in colorectal cancer. Thromb Haemost 111: 483-490, 2014.

16 Nyasavajjala SM, Runau F, Datta S, Annette H, Shaw AG and Lund JN: Is there a role for pre-operative thrombocytosis in the management of colorectal cancer? Int J Surg 8: 436-438, 2010.

17 Moher D, Liberati A, Tetzlaff J, Altman DG and Group P: Preferred reporting items for systematic reviews and meta-analyses: the PRISMA statement. Ann Intern Med 151: 264-269, W264, 2009.

18 Kim HJ, Choi GS, Park JS, Park S, Kawai K and Watanabe T: Clinical significance of thrombocytosis before preoperative chemoradiotherapy in rectal cancer: predicting pathologic tumor response and oncologic outcome. Ann Surg Oncol 22: 513-519, 2015.

19 Qiu MZ, Yuan ZY, Luo HY, Ruan DY, Wang ZQ, Wang FH, Li $\mathrm{YH}$ and $\mathrm{Xu} \mathrm{RH}$ : Impact of pretreatment hematologic profile on survival of colorectal cancer patients. Tumour Biol 31: 255-260, 2010.

20 Kaneko M, Nozawa H, Sasaki K, Hongo K, Hiyoshi M, Tada N, Murono K, Nirei T, Kawai K, Sunami E, Tsuno NH and Kitayama J: Elevated neutrophil to lymphocyte ratio predicts poor prognosis in advanced colorectal cancer patients receiving oxaliplatin-based chemotherapy. Oncology 82: 261-268, 2012.

21 Toiyama Y, Inoue Y, Kawamura M, Kawamoto A, Okugawa Y, Hiro J, Saigusa S, Tanaka K, Mohri Y and Kusunoki M: Elevated platelet count as predictor of recurrence in rectal cancer patients undergoing preoperative chemoradiotherapy followed by surgery. Int Surg 100: 199-207, 2015.

22 Kitayama J, Yasuda K, Kawai K, Sunami E and Nagawa H: Circulating lymphocyte number has a positive association with tumor response in neoadjuvant chemoradiotherapy for advanced rectal cancer. Radiat Oncol 5: 47-50, 2010.

23 Ishizuka M, Nagata H, Takagi K, Iwasaki Y and Kubota K: 
Combination of platelet count and neutrophil to lymphocyte ratio is a useful predictor of postoperative survival in patients with colorectal cancer. Br J Cancer 109: 401-407, 2013.

24 Roxburgh CS, Wallace AM, Guthrie GK, Horgan PG and McMillan DC: Comparison of the prognostic value of tumour- and patient-related factors in patients undergoing potentially curative surgery for colon cancer. Colorectal Dis 12: 987-994, 2010.

25 Dymicka-Piekarska V, Kemona H, Piotrowski Z, Gryko M, Milewski Z and Matowicka-Karna J: Does colorectal cancer influence platelet activation? Przegl Lek 60: 716-718, 2003.

26 Lin MS, Huang JX, Zhu J and Shen HZ: Elevation of platelet count in patients with colorectal cancer predicts tendency to metastases and poor prognosis. Hepatogastroenterology 59: 1687$1690,2012$.

27 Yasuda K, Sunami E, Kawai K, Nagawa H and Kitayama J: Laboratory blood data have a significant impact on tumor response and outcome in preoperative chemoradiotherapy for advanced rectal cancer. J Gastrointest Cancer 43: 236-243, 2012.

28 Kilincalp S, Coban S, Akinci H, Hamamci M, Karaahmet F, Coskun Y, Ustun Y, Simsek Z, Erarslan E and Yuksel I: Neutrophil/ lymphocyte ratio, platelet/lymphocyte ratio, and mean platelet volume as potential biomarkers for early detection and monitoring of colorectal adenocarcinoma. Eur J Cancer Prev 24: 328-333, 2015.

29 Monreal M, Fernandez-Llamazares J, Pinol M, Julian JF, Broggi M, Escola D and Abad A: Platelet count and survival in patients with colorectal cancer - a preliminary study. Thromb Haemost 79: 916-918, 1998.

30 Costantini V, Zacharski LR, Moritz TE and Edwards RL: The platelet count in carcinoma of the lung and colon. Thromb Haemost 64: 501-505, 1990.

31 Tartter PI: Pretreatment prognostic factors in colorectal cancer patients with synchronous liver metastases. Eur J Surg Oncol 13: 485-491, 1987.

32 Wojtukiewicz MZ, Zacharski LR, Moritz TE, Hur K, Edwards RL and Rickles FR: Prognostic significance of blood coagulation tests in carcinoma of the lung and colon. Blood Coagul Fibrinolysis 3: 429-437, 1992.

33 Josa V, Krzystanek M, Eklund AC, Salamon F, Zarand A, Szallasi Z and Baranyai Z: Relationship of postoperative thrombocytosis and survival of patients with colorectal cancer. Int J Surg 18: 1-6, 2015.

34 Nozoe T, Iguchi T, Maeda T, Kohno M and Ezaki T: Simple criteria to predict prognosis in colorectal carcinoma based on lymphopenia and thrombocytosis. Mol Clin Oncol 1: 171-174, 2013.

35 Carruthers R, Tho LM, Brown J, Kakumanu S, McCartney E and McDonald AC: Systemic inflammatory response is a predictor of outcome in patients undergoing preoperative chemoradiation for locally advanced rectal cancer. Colorectal Dis 14: e701-707, 2012.

36 Guo T, Krzystanek M, Szallasi Z and Szallasi A: Thrombocytosis portends adverse prognostic significance in patients with stage II colorectal carcinoma. F1000Res 3: 180 (eCollection), 2014.

37 Paik KY, Lee IK, Lee YS, Sung NY and Kwon TS: Clinical implications of systemic inflammatory response markers as independent prognostic factors in colorectal cancer patients. Cancer Res Treat 46: 65-73, 2014.

38 Neal CP, Mann CD, Sutton CD, Garcea G, Ong SL, Steward WP, Dennison AR and Berry DP: Evaluation of the prognostic value of systemic inflammation and socioeconomic deprivation in patients with resectable colorectal liver metastases. Eur J Cancer 45: 5664, 2009.

39 Choi KW, Hong SW, Chang YG, Lee WY, Lee B, Paik IW and Lee H: Inflammation-based score (Glasgow prognostic score) as an independent prognostic factor in colorectal cancer patients. Ann Surg Treat Res 86: 309-313, 2014.

40 Wan S, Lai Y, Myers RE, Li B, Hyslop T, London J, Chatterjee D, Palazzo JP, Burkart AL, Zhang K, Xing J and Yang H: Preoperative platelet count associates with survival and distant metastasis in surgically resected colorectal cancer patients. J Gastrointest Cancer 44: 293-304, 2013.

41 Neal CP, Cairns V, Jones MJ, Masood MM, Nana GR, Mann CD, Garcea $G$ and Dennison AR: Prognostic performance of inflammation-based prognostic indices in patients with resectable colorectal liver metastases. Med Oncol 32: 144-150, 2015.

42 Kozak MM, von Eyben R, Pai JS, Anderson EM, Welton ML, Shelton AA, Kin C, Koong AC and Chang DT: The prognostic significance of pretreatment hematologic parameters in patients undergoing resection for colorectal cancer. Am J Clin Oncol, 2015 (ePub ahead of print, PMID 25756348).

43 Cravioto-Villanueva A, Luna-Perez P, Gutierrez-de la Barrera M, Martinez-Gomez H, Maffuz A, Rojas-Garcia P, Perez-Alvarez C, Rodriguez-Ramirez S, Rodriguez-Antezana E and RamirezRamirez L: Thrombocytosis as a predictor of distant recurrence in patients with rectal cancer. Arch Med Res 43: 305-311, 2012.

44 Kawai K, Kitayama J, Tsuno NH, Sunami E and Watanabe T: Thrombocytosis before pre-operative chemoradiotherapy predicts poor response and shorter local recurrence-free survival in rectal cancer. Int J Colorectal Dis 228: 527-535, 2013.

45 Josa V, Krzystanek M, Vass T, Lang T, Juhasz V, Szilagyi K, Tihanyi B, Harsanyi L, Szallasi Z, Salamon F and Baranyai Z: Thrombocytosis of liver metastasis from colorectal cancer as predictive factor. Pathol Oncol Res 21: 991-997, 2015.

46 Higgins J and Green S (eds): Cochrane Handbook of Systematic Reviews of Interventions. Wiley-Blackwell, Chichester, UK, 2008.

47 Semple JW, Italiano JE, Jr. and Freedman J: Platelets and the immune continuum. Nat Rev Immunol 11: 264-274, 2011.

48 Kaser A, Brandacher G, Steurer W, Kaser S, Offner FA, Zoller H, Theurl I, Widder W, Molnar C, Ludwiczek O, Atkins MB, Mier JW and Tilg H: Interleukin-6 stimulates thrombopoiesis through thrombopoietin: role in inflammatory thrombocytosis. Blood 98: 2720-2725, 2001.

49 Gay LJ and Felding-Habermann B: Contribution of platelets to tumour metastasis. Nat Rev Cancer 11: 123-134, 2011.

50 Lyman GH and Kuderer NM: The strengths and limitations of meta-analyses based on aggregate data. BMC Med Res Methodol 5: 14, 2005.

51 Higgins JP, Thompson SG, Deeks JJ and Altman DG: Measuring inconsistency in meta-analyses. BMJ 327: 557-560, 2003.

$52 \mathrm{Men} \mathrm{H}$, Liang $\mathrm{C}$ and $\mathrm{Yu}$ M: Thrombocytosis as a prognostic factor in patients with renal cell carcinoma: a meta-analysis of literature. J Cancer Res Ther 11: 67-72, 2015. 